\title{
Recursos da Web 2.0 e suas contribuições na Prática Pedagógica do Ensino de Biblioteconomia
}

\author{
Applying Web 2.0 Resources to Educational Practice
}

\author{
Ronaldo Ferreira Araújo \\ Doutorando em Ciência da Informação (UFMG) \\ Professor do Curso de Biblioteconomia (UFAL) \\ E-mail: ronaldfa@gmail.com
}

\section{Resumo}

\begin{abstract}
Aborda utilização de recursos da web 2.0 na prática pedagógica no apoio ao processo de ensino e aprendizagem. Relata a experiência desenvolvida durante a realização da disciplina "Informática aplicada à Biblioteconomia II" do curso de Biblioteconomia da Universidade Federal de Alagoas (UFAL) durante o primeiro semestre do ano de 2011. O objetivo foi analisar a possibilidade de se utilizar recursos da web 2.0 como aportes metodológicos ao ensino da disciplina. Foi criada uma hastag para o acompanhamento e discussão da disciplina no Twitter. Por meio de busca manual no próprio Twitter e uso da Plataforma Topsy monitorou-se 514 mensagens compartilhadas pelos alunos e professor. Analisa a participação e engajamento dos alunos na disciplina por meio: da distribuição das mensagens por mês, dia da semana e horário do dia; da interatividade, verificada a partir dos mentions, replies, e retweets. Como resultado verificou-se uma aprendizagem distributiva e contínua na qual o assunto discutido ultrapassa as limitações espaço-temporal da sala de aula, com envolvimento ativo e exercício da autonomia por parte dos alunos. Por fim são apresentadas algumas considerações dos alunos sobre o uso do microblog.
\end{abstract}

Palavras-chave: Web 2.0. Prática pedagógica. Twitter. Biblioteca 2.0.

\begin{abstract}
Discuss about the use of web 2.0 resources in teaching practice to support the process of teaching/learning. We report the experience developed during the "Informatics applied to librarianship II" discipline of the University Federal de Alagoas (UFAL) Librarianship Course, during the first half of 2011. The aim was to analyze the possibility of using web 2.0 resources as methodological contributions to that discipline. It was created a hastag for monitoring and discussion of the subject on Twitter. Through manual search in Twitter itself and use the Topsy Platform it was monitored 514 messages shared by students and teacher. Examines the participation and engagement of students in the discipline through: the distribution of messages per month, day of week and time of day; interactivity, seen from the mentions, replies and retweets. The results are a distributive and continuous learning in which the topics discussed overcomes the space-time limitations of the classroom, with active involvement and autonomy exercise by the students.
\end{abstract}

Keywords: Web 2.0. Education practice. Twitter. Library 2.0. 


\section{Considerações iniciais}

Os constantes avanços da tecnologia da informação e comunicação fazem com que a transferência de dados e as trocas informacionais sejam cada vez mais rápidas e instantâneas. A internet, como veículo de comunicação, a web como plataforma de conteúdos, produtos e serviços e as redes sociais na internet (RECUERO, 2009) como canais de circulação de informação e conexão entre os atores desempenham esta função com eficiência e apresentam inúmeras contribuições no contexto educacional.

A web passou por mudanças significativas que reconfiguram a centralidade da rede e o papel dos usuários. A web 2.0 é considerada a segunda geração da web e caracteriza-se por potencializar as formas de publicação, compartilhamento e organização de informações, além de ampliar os espaços para a interação entre os envolvidos nesse processo.

Segundo Primo (2007) a web 2.0 tem repercussões sociais importantes, que potencializam processos de trabalho coletivo, de troca afetiva, de produção e circulação de informações, de construção social de conhecimento apoiada pela informática. Os recursos da web 2.0, suas formas interativas e suas contribuições para a prática pedagógica, serão aqui discutidos, para em seguida ser apresentada uma experiência prática que envolveu o uso desses recursos no percurso da disciplina "BIBL013 - Informática Aplicada à Biblioteconomia II" do curso de Biblioteconomia da Universidade Federal de Alagoas (UFAL).

A proposta na experiência a ser apresentada foi trabalhar com os recursos da web 2.0 para além de simples conteúdo programático a ser estudado na disciplina incluindo-os na proposta pedagógica como recurso didático e assim familiarizar a turma com esses ambientes, explorando o potencial de comunicação e interação que eles possibilitam para promover a reflexão teórica e prática em torno da "Biblioteca 2.0" (BLATTMANN; CORREAA DA SILVA, 2007; MANESS, 2007) e discutir sobre a formação do "Bibliotecário 2.0”.

De acordo com Maness (2007, p.44), a "Biblioteca 2.0” é definida como "a aplicação de interação, colaboração, e tecnologias multimídia baseadas em web para serviços e coleções de bibliotecas baseados em web". O autor sugere que esta definição seja adotada pela comunidade biblioteconômica.

InCID: R. Ci. Inf. e Doc., Ribeirão Preto, v. 4, n. 1, p. 163-181, jan./jun. 2013. 
Para Abram (2007) a melhor maneira de familiarizar os bibliotecários com a "Biblioteca 2.0" é explorando os recursos da internet e da web 2.0 com foco no aprendizado constante a partir da vivência diária. Para isso o uso dos recursos deve ser incorporado a sua prática (enquanto usuário e profissional da informação) e ao cotidiano na biblioteca.

\title{
A prática pedagógica no ensino de Biblioteconomia e os recursos tecnológicos
}

A reflexão sobre a prática pedagógica de docentes de Biblioteconomia e Ciência da Informação já foi objeto de estudos de autores como Ferreira (1999, 2000a, 2000b), Hillesheim (2001), Rodrigues (2008, 2011) e Castro (2007). Alguns trabalhos destacam a figura do professor na formação, mas com enfoques distintos.

Ao traçar um olhar para a compreensão do pensamento do professor e de suas habilidades, a partir dos conhecimentos e estratégias utilizadas por ele em sala de aula Ferreira (2000b) trabalha com a noção de transposição didática, considerada

\begin{abstract}
um processo resultante de um trabalho intelectual do professor, que é feito considerando muitas variáveis, como conteúdo, aluno, realidade, entre outros. Exige uma prática pedagógica reflexiva para que o docente adapte os conteúdos para serem desenvolvidos em sala de aula, facilitando a aprendizagem (FERREIRA, 2000b, p.61).
\end{abstract}

A partir de entrevistas feitas com as professoras do curso de Biblioteconomia da Faculdade de Biblioteconomia e Comunicação da Universidade Federal do Rio Grande do Sul, Ferreira (2000b) percebe e destaca, dentre outras impressões, ter verificado uma preocupação das professoras em diversificar os procedimentos, par tornar as dinâmicas das aulas mais atraentes para os alunos, no intuito de facilitar a sua aprendizagem.

De acordo com Hillesheim (2001, p.51) "os docentes que hoje atuam nas universidades são desafiados a criarem projetos que trabalhem o conhecimento aliado à pesquisa, e também a participação efetiva dos alunos no processo educativo". A autora em seu estudo além de ouvir professores entrevistou também os alunos do Curso de Biblioteconomia da Universidade Federal de Santa Catarina observou que

há nos discursos dos alunos uma ânsia por formas inovadoras das práticas pedagógicas. $\mathrm{O}$ processo pode ser difícil e desafiador, mais vale a pena romper com o tradicional e buscar metodologias inovadoras que possibilitam uma maior participação e interação entre docente e aluno (HILLESHEIM, 2001, p.151). 
O estudo de Rodrigues (2008, p.15) foi realizado "com base nos fundamentos do paradigma emergente" por meio de reflexões em torno de uma proposta de ensino aprendizagem para as áreas de Biblioteconomia e Ciência da Informação, "com o intuito de colaborar para uma resignificação desse processo" (RODRIGUES, 2011, p. 1833).

Em análise às práticas pedagógicas, as aulas expositivas dialogadas, atividades de interação entre os alunos, estudo de textos, atividades práticas e de laboratórios, foram as metodologias mais usadas em sala de aula para transmissão do conhecimento aos alunos, conforme estudo de Rodrigues (2011, p.1843), contudo segundo a autora o uso de recursos tecnológicos e midiáticos praticamente não foram mencionados pelos entrevistados, o que "deixa de possibilitar uma alternativa para aprimorar o conhecimento transmitido pelo professor".

Dos autores citados, Castro (2007) pode ser considerado o que mais sistematicamente tem discutido questões sobre a formação do profissional da informação. Ao analisar as tendências pedagógicas que têm orientado a prática docente no ensino de Biblioteconomia e Ciência da Informação, o autor considerou que a incorporação das tecnologias de comunicação e de informação resultantes do processo de mudança que ocorreu no ensino biblioteconômico na década de 1950, favoreceu a transformação das técnicas e das teorias do campo da Biblioteconomia, que ele denomina de característica técnico-científica. De acordo com Rodrigues (2011) essa característica é “integradora das tendências pedagógicas tradicionais [...], que julgamos que sejam as que têm influenciado a formação do bibliotecário brasileiro, desde a sua gênese até o momento atual".

A própria Associação Brasileira de Educação em Ciência da Informação (ABECIN) sempre se preocupou com a discussão curricular e com as reflexões sobre as bases teóricas e pedagógicas que devem nortear o ensino e a formação na área. Em seu o relatório de gestão 2004/2007 (ABECIN, 2007) encontramos registros sobre o uso pedagógico das tecnologias da informação e comunicação (TICs) no processo de ensino-aprendizagem em CI e da necessidade do planejamento da integração das TICs na cultura de cada escola/curso. Nessa mesma perspectiva o trabalho explora os recursos da web 2.0 como expressões dessas tecnologias no apoio ao ensino. 


\section{Recursos da web 2.0 no contexto educacional: wikis, (micro)blogs e redes sociais}

As primeiras experiências de Educação a Distância (EAD) relatam a utilização de mídias "convencionais" como impressos, rádio, TV e computador desconectado da rede, na perspectiva de um relacionamento assíncrono de um para muitos ou de um para um. Com o advento da internet e as potencialidades da EAD via web, a principal mudança está na possibilidade de uma interação síncrono, em tempo real, independentemente da localização física dos participantes do grupo.

De acordo com Haguenauer e Pedroso (2003) a aprendizagem colaborativa e o trabalho colaborativo tornam-se figuras centrais no EAD via web, viabilizadas pelas ferramentas de comunicação e interação das plataformas de ensino. Conforme as autoras, vários métodos desenvolvidos e utilizados para a $E A D$ via web vêm sendo aproveitados como apoio ao ensino presencial, possibilitando uma hibridização do ensino a distância e ensino presencial - na concepção do ensino semipresencial, que proporciona uma nova cultura do ensino on-line junto a alunos e professores.

Os recursos da web 2.0 ganham cada vez mais centralidade nesse contexto. Grosseck, Marinho e Tárcia (2009) ao refletirem sobre a EAD baseada na web 2.0 indicam uma perspectiva pedagógica que presume modificações no método de ensino, permitindo, por exemplo, aos alunos colaborar, envolver-se ativamente na criação de conteúdos e compartilhar ou trocar informações on-line. Os autores listam algumas características e contribuições da web 2.0 que a coloca como vetor de mudanças no contexto educacional, destacam-se algumas:

modifica continuamente o paradigma clássico da geração e da transmissão de conhecimento, ao ser espaço de leitura e escrita em diversas linguagens interativas; longe de dividir ou de estabelecer "guetos" de informação, cria novas oportunidades, especialmente de reunião e conexão, por meio de redes sociais; favorece aqueles aos quais ensinamos a desistir da escuta passiva em favor do envolvimento ativo; permite que os estudantes aprendam uns com os outros, em diversos graus, ensejando o exercício da autonomia para a tomada de decisões e a ação; transforma os tradicionais métodos pedagógicos com os quais a escola vem funcionando, oferecendo alternativas em uma sociedade marcada pela pluralidade das fontes de informação e por acesso a elas cada vez mais facilitado; cria as premissas para a aprendizagem personalizada e cooperativa ou colaborativa, com estudantes e professores apoiando-se mutuamente, para aprendizagem distributiva e contínua; permite maior distribuição espacial do conhecimento; possibilita a criação de verdadeiras comunidades de aprendizagem; reforça o princípio da partilha de informações ou competências, no exercício da inteligência coletiva (LÉVY, 1998). (GROSSECK; MARINHO; TÁRCIA, 2009, p. 116-117. Grifo nosso)

InCID: R. Ci. Inf. e Doc., Ribeirão Preto, v. 4, n. 1, p. 163-181, jan./jun. 2013. 
O Moodle ${ }^{1}$, o Amadeus ${ }^{2}$ e outras plataformas de ensino (ambientes virtuais de aprendizagem) apresentam parte dessas características a partir de funções que contribuem com aprendizagem colaborativa: fóruns de discussão, blogs e wikis. Mas quando são adotadas por instituições de ensino e usadas na EAD ou mesmo no ensino presencial, podem ser consideradas "fechadas", pois o acesso e a interação são restritos aos professores e alunos em turmas previamente cadastrados de acordo com a política institucional adotada.

Nesse contexto o uso de recursos da web 2.0 na educação por meio de serviços abertos, como é o caso dos wikis, blogs, dos microblogs e das redes sociais na internet (BLATTMANN; CORRÊA DA SILVA, 2007; CAMARGO, 2008; PIMENTEL et al., 2009; RECUERO, 2009; GUTIERREZ, 2010; LIMA, 2011) ganham cada vez mais espaço. Esses ambientes se tornam ricos espaços de trocas e fazem com que o assunto discutido ultrapasse as limitações espaço-temporal da sala de aula uma vez que "ganha" a rede e suas múltiplas possibilidades.

A aplicação mais popular da web 2.0 na educação são os "wikis, blogs e podcasts". Reconhecidos pelos autores como "softwares sociais", ou "tecnologias da web 2.0 (que) representam um revolução quanto a web 1.0 na maneira de gerenciar e dar sentido ou ofertar a informação online" (BLATMANN; CORRÊA DA SILVA, 2007, p.194). Os wikis permitem maior interatividade por meio da colaboração entre editores e isso os torna bem apropriados para o uso educacional, pois dá centralidade ao usuário (aluno) e o elege como produtor de conteúdo em uma perspectiva de construção coletiva.

Tais tecnologias deveriam fazer parte da formação do professor "com ênfase na formação e manutenção de redes de relações sociais" na construção de uma "cultura digital que se fundamenta em tecnologias e processos livres e abertos", para que continuem a crescer e conquistar seu espaço, como é o caso das redes online de professores que usam blogs (GUTIERREZ, 2010, p.243).

Os blogs são gêneros comunicacionais emergentes que vêm se destacando no cenário digital brasileiro, sua usabilidade e lógica de comunicação interativa contribuem com o processo de socialização do conhecimento, podendo inclusive ser considerados tanto "uma

\footnotetext{
${ }^{1}$ Software livre de apoio à aprendizagem, desenvolvido em php e com banco de dados MySQL, PostgreSQL, Oracle, Access, Interbase, através da colaboração da comunidade virtual. Disponível em: http://moodle.org

${ }^{2}$ Sistema de gestão de aprendizagem para Educação a Distância baseado no conceito de blended learning (uma mistura de aulas a distância com presenciais). Disponível em: http://www.softwarepublico.gov.br/

${ }^{3}$ Trata-se de um arquivo de áudio em suporte digital, geralmente em formato '.mp3' ou '.aac', publicado na internet. A palavra é composta pela junção de Pod (Personal On Demand) e broadCAST.
}

InCID: R. Ci. Inf. e Doc., Ribeirão Preto, v. 4, n. 1, p. 163-181, jan./jun. 2013. 
fonte utilitária de informação e como canal de disseminação da informação" (ARAÚJO; VIEIRA, 2012, p.66)

O microblog é uma variação do blog (CAMARGO, 2008; PIMENTEL et al., 2009), pois contém os mesmos princípios de um blog com certas limitações em relação à quantidade de informação que pode ser trafegada e a maneira como a mensagem trafega dentro desta rede social, que no blog funciona sob outra lógica. O Twitter (www.twitter.com), lançado em 2006 é um bom exemplo de microblog e além de ser considerado uma rede social (BOYD; ELLISON, 2007; RECUERO; ZAGO, 2010; PEREIRA; CRUZ, 2010) funciona como um servidor para microblogs no qual o usuário cria uma conta (“@+nome” - pública ou privada) que lhe dá acesso a uma página onde é possível incluir foto, escolher imagem de fundo, construir um perfil (bio) e publicar mensagens (tweets). As relações se estabelecem a partir da escolha de quem o usuário deseja seguir (following) e por quem ele poderá ser seguido (followers). A mensagem postada por um usuário aparece automaticamente na página principal ou linha do tempo (timeline) da sua rede de seguidores.

A comunicação e intercâmbio de informações entre os usuários, o que indicam a interatividade da rede, podem ocorrer de três formas: o usuário ao postar uma mensagem menciona (mention) um outro usuário (da sua rede ou não); ao ver uma atualização em sua timeline o usuário pode responder (reply) ou reproduzir (retweet ou RT) a mensagem.

O que caracteriza o Twitter como microblog é sua lógica de comunicação baseada no Short Message Service (SMS) na qual oferece apenas 140 caracteres de espaço para escrever. No teor da mensagem o usuário pode usar o recurso da hashtag indicado pelo símbolo "\#” que funciona como marcação de palavras-chave, que agregam valor semântico aos tweets, auxilia na categorização das mensagens e no acompanhamento de determinados assuntos. Os nomes ${ }^{4}$ e hashtags mais usadas pelos usuários se tornam populares e podem aparecer no Trending Topics 5 .

De acordo com Recuro e Zago (2010) o Twitter é um site de rede social propícia para o estudo de difusão de informações. Por mesclar características de blog, SMS e mensageiro instantâneo, o microblog apresenta um caráter informacional, visto que nas trocas informacionais os usuários podem incrementar as mensagens curtas e incluir links de sites

\footnotetext{
${ }^{4}$ Nomes próprios, nomes de empresas, de produtos ou de marcas.

${ }^{5}$ Indicam tópicos de tendência e refletem o que há de mais popular no microblog no mundo todo. Maiores informações: http://support.twitter.com/articles/101125-about-trending-topics
}

InCID: R. Ci. Inf. e Doc., Ribeirão Preto, v. 4, n. 1, p. 163-181, jan./jun. 2013. 
com notícias, imagens, vídeos, ou mesmo postar fotos próprias, por meio de aplicativos como o Twitpic ${ }^{6}$.

Ao discutirem sobre o uso potencial de microblogs como o Twitter na educação, Pimentel e outros (2009) destacam que no contexto do ciberespaço (LÉVY, 2000) os conceitos de comunicação e interação são retomados e analisados na busca por um melhor aproveitamento da Rede, em vista da compreensão do "como" se processa o ensinoaprendizagem, a partir do entendimento de que a educação é gerada pela mediação que ocorre nos espaços e ambientes virtuais.

Falar em mediação nesse contexto é necessariamente repensar o papel, até então unilateral, do professor em relação ao aluno e transferi-lo para um lugar que pode inclusive ser descentralizado, mas jamais perca sua atuação de influenciar, instigar e motivar. Isso implica dizer também que o aluno assume um papel mais autônomo e crítico de criação e colaboração.

Ao refletir sobre a epistemologia do professor, Becker (1998) apresenta três concepções pedagógicas que podem estar presentes em sala de aula. Uma delas é a do ensino centrado na relação entre docente e aluno, na qual, segundo o autor nenhum dos dois dispõe de superioridade prévia, uma vez que, o docente traz sua bagagem, o aluno também, porém são bagagens diferenciadas que entram na relação de ensino-aprendizagem. Consideramos que essa concepção se materializa em uma prática pedagógica interativa, e que com a incorporação de recursos da web 2.0 no apoio ao ensino pode contribuir nessa direção.

\section{Prática pedagogia interativa: formando bibliotecários $\mathbf{2 . 0}$}

Para contribuir com a reflexão sobre uma prática pedagógica interativa no curso de biblioteconomia nos moldes dos princípios da web 2.0 de participação e colaboração foi indicado para a turma o uso do microblg Twitter no apoio as atividades da disciplina "BIBL013 - Informática Aplicada à Biblioteconomia" do Curso de Biblioteconomia da Universidade Federal de Alagoas. A hashtag sugerida para identificar a disciplina e possibilitar o acompanhamento das discussões ao longo do semestre foi \#infobiblio.

\footnotetext{
${ }^{6}$ Serviço que permite ao usuário do Twitter compartilhar fotos em tempo real: $\underline{\text { http://twitpic.com/ }}$ InCID: R. Ci. Inf. e Doc., Ribeirão Preto, v. 4, n. 1, p. 163-181, jan./jun. 2013.
} 
A partir do monitoramento da hashtag por meio de 'buscas manuais' na própria plataforma do Twitter e na aplicação Topsy ${ }^{7}$ foram identificadas 514 mensagens, distribuídas no período de fevereiro a junho de 2011. A participação e engajamento dos alunos na disciplina foram analisados por meio da distribuição das mensagens por mês, dia da semana e horário do dia; da interatividade a partir dos mentions, replies e retweets. No Gráfico 1 é possível observar a distribuição das mensagens por mês.

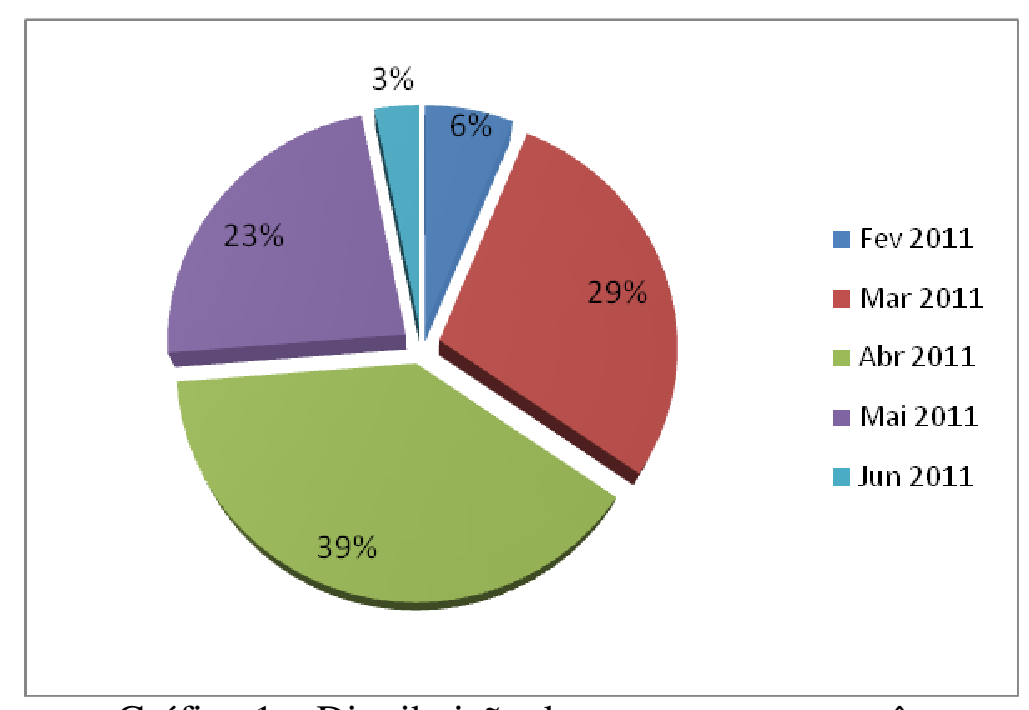

Gráfico 1 - Distribuição das mensagens por mês

A distribuição das mensagens revela-se crescente no período de fevereiro à abril e decresce de abril para junho. Atribui-se o baixo índice de mensagens no mês de fevereiro e junho devido o semestre letivo, geralmente, iniciar na segunda quinzena de fevereiro e finalizar pouco depois da primeira quinzena de junho. $\mathrm{O}$ mês de abril apresenta o maior número de mensagens, foram 201 , correspondendo a $39 \%$ do total.

O Gráfico 2 representa a distribuição das mensagens por dia da semana.

\footnotetext{
${ }^{7}$ Aplicação web desenvolvida pela Topsy Labs, Inc. que indexa grande quantidade de conteúdos postados nas redes sociais. Acesso em: http://topsy.com/
}

InCID: R. Ci. Inf. e Doc., Ribeirão Preto, v. 4, n. 1, p. 163-181, jan./jun. 2013. 


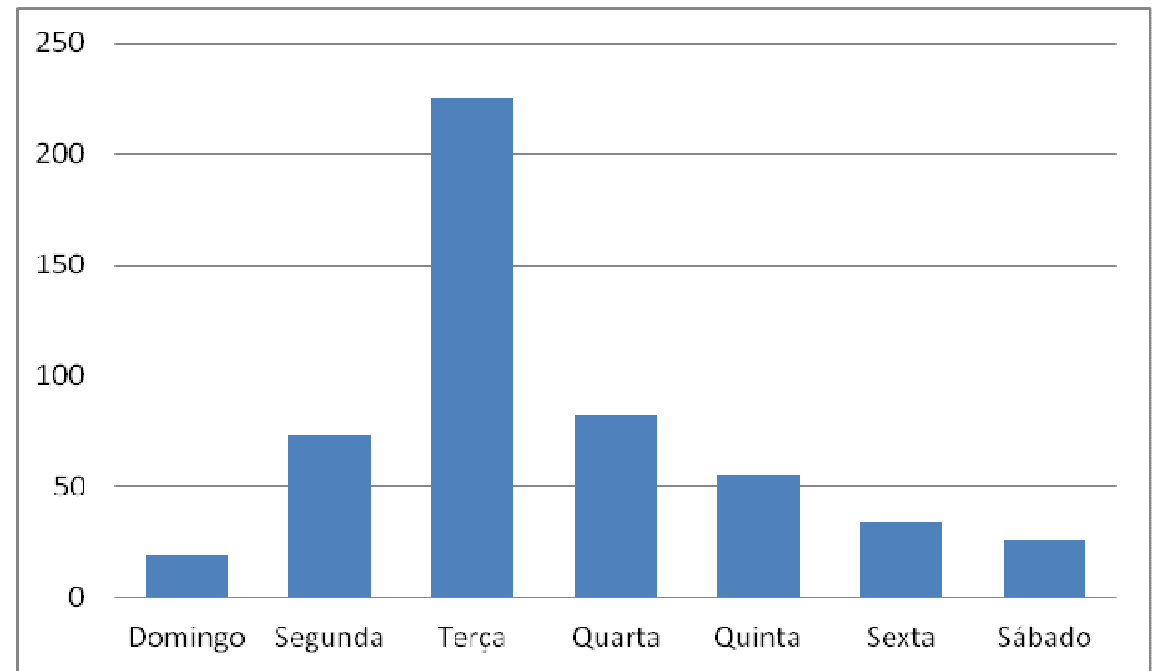

Grafico 2 - Distribuição das mensagens por dia da semana

A disciplina em questão foi ministrada às terças-feiras, e como esperado, foi o dia da semana com o maior número de mensagens, foram 225 , correspondendo a $43,77 \%$ do total. $\mathrm{O}$ que começa a interessar esta pesquisa, por revelar as contribuições do uso dos recursos de web 2.0 no ensino é a noção de aprendizagem distributiva e contínua (GROSSECK, MARINHO; TÁRCIA, 2009). Assim, o assunto pode até começar em da sala de aula, mas ultrapassa suas limitações físicas, seu registro no ciberespaço ganha movimento, continuidade e proliferação por meio das redes. Isso pode ser confirmado por $56,23 \%$ das mensagens distribuídos em outros dias da semana, incluindo sábado $(5,6 \%)$ e domingo $(3,7 \%)$.

O mesmo pode ser identificado ao observarmos o Gráfico 3, com a distribuição das mensagens por horário do dia.

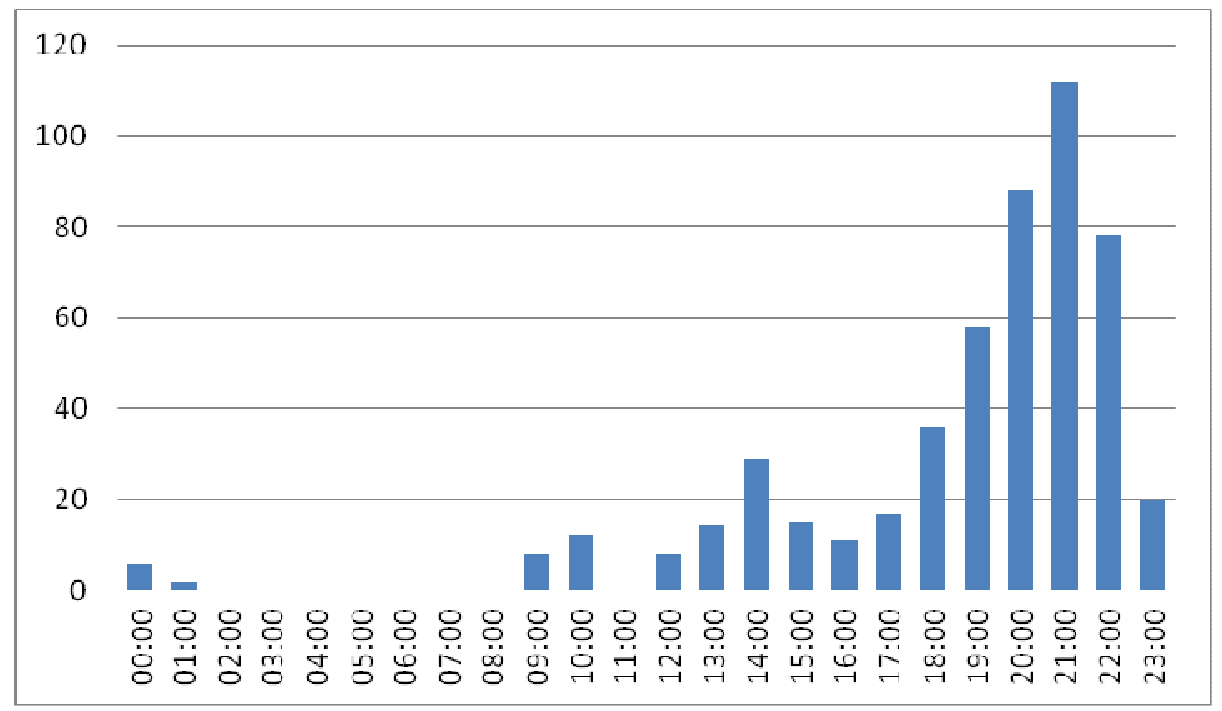

Gráfico 3 - Distribuição das mensagens por horário do dia 
A disciplina em questão foi ministrada no período das $19 \mathrm{~h}$ as $22 \mathrm{~h} 20$, o que corresponde exatamente ao maior número de mensagens, somaram 336 , correspondendo a $65,37 \%$ do total. Ainda assim, temos um restante de 178 mensagens $(34,63 \%)$ distribuídas em outros horários do dia.

Em relação à interatividade, permitida pelo uso do Twitter, identificou 153 mensagens interativas o que corresponde a 29,77\%, das quais 92 foram mentions ou replies e 61 Retweets. A representatividade das interações pode ser visualizada na rede conforme os Grafos 1 e 2 . O nome dos atores-alunos foi retirado para preservar a identidade e substituído por '@A seguido de numeração crescente: de @A1 a @A21'; as demais indicações ficam assim: Professor = @Prof; Alunos de outros períodos = @B...; Egresso = @Eg; Ator-externo $=@ E x ;$ Os outros atores tiveram a identidade preservada e são na sua maioria perfis institucionais.

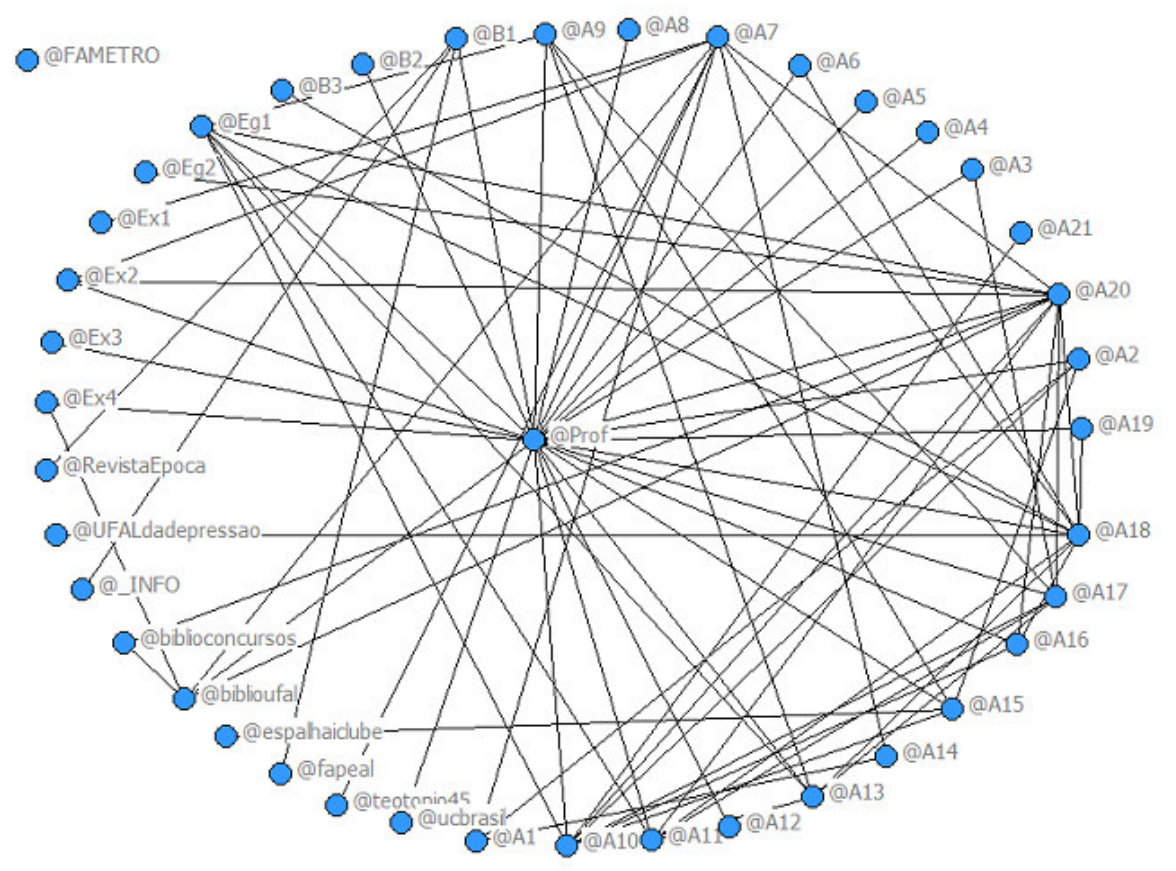

Grafo 1 - Interatividade entre alunos e professor a partir de replies e RTs.

Outra questão relacionada ao uso dos recursos da web 2.0 no ensino, em especial, de redes sociais abertas, como o caso do Twitter, é que os alunos não ficam restritos ao grupo da sala de aula, uma vez que essas plataformas expressam a "máxima" da web 2.0, ou seja, estão embasadas na conexão em rede de "todos para todos" como enfatiza Lévy (2000). E nessa perspectiva sustentada pela cibercultura, as redes exprimem ideias, saberes e mobilizam pessoas e grupos sociais na multiplicidade de suas relações (LÉVY, 1997).

InCID: R. Ci. Inf. e Doc., Ribeirão Preto, v. 4, n. 1, p. 163-181, jan./jun. 2013. 
Consideramos que esses apontamentos de Levy podem ser verificados no grafo apresentado, uma vez que mesmo tendo apenas 21 alunos matriculados na disciplina, foram mapeados 41 atores envolvidos em sua hashtag, que estabeleceram 101 conexões $(252,5 \%)$. $\mathrm{O}$ ator que não apresenta conexão recíproca ou unidirecional com nenhum outro ator é chamado de "nó solto". É o caso da @FAMETRO ${ }^{8}$.

De acordo com método de análise de redes sociais que mede a centralidade da rede, temos o @ Prof com o maior grau de entrada, 19 (18,81\%), e por sua vez possui também o maior grau de saída 25 (24,75\%). Essa centralidade era esperada, segundo Cunha (1998, p.33) o agente principal das decisões no campo da formação é o professor, sendo quem "concretiza a definição pedagógica e, na estrutura acadêmica de poder, representa a maior força”.

Sabe-se que no contexto de uma prática pedagógica nos moldes em que se propõe no presente artigo, o professor desempenha o papel de intermediador e "motivador", assim, ainda que ele ocupe a centralidade da rede, os atores tendem a continuar interagindo em sua ausência, o que pode ser verificado no Grafo 2 , sobre a interatividade da rede sem a figura do professor.

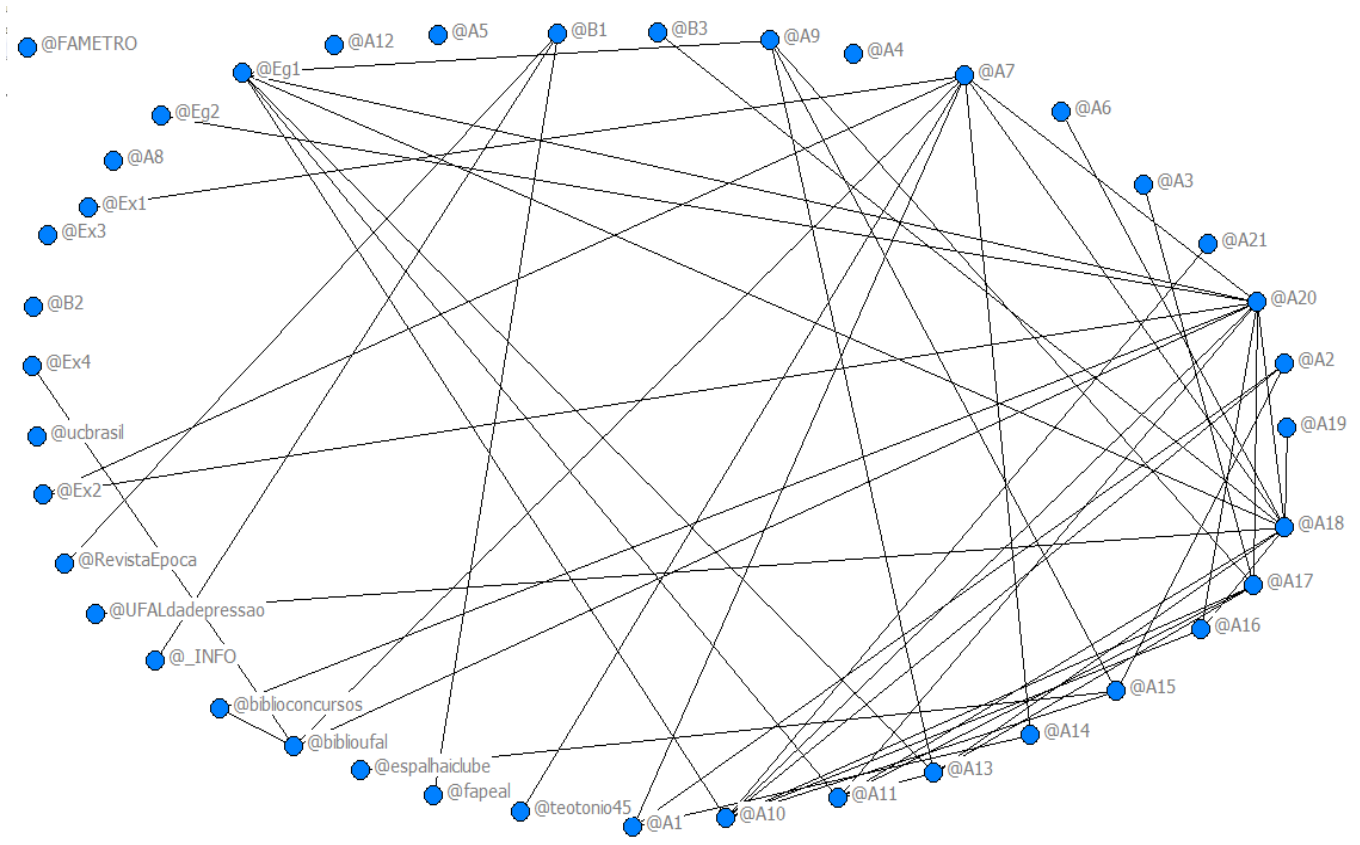

Grafo 2 - Interatividade entre alunos a partir de replies e $R T s$, sem a figura do professor.

\footnotetext{
${ }^{8}$ Perfil Institucional da Faculdade Metropolitana de Manaus: https://twitter.com/Fametro . Interagiu com a hashtag da turma no momento em que foi mencionada por um grupo de alunos que apresentava no "Seminário sobre produtos e serviços da informação na era digital" com trabalho sobre os recursos da web 2.0 usados por bibliotecas universitárias da região Norte.
}

InCID: R. Ci. Inf. e Doc., Ribeirão Preto, v. 4, n. 1, p. 163-181, jan./jun. 2013. 
A rede permanece conectada e alguns atores se mostram mais conectados que outros, seja entre o membros da sala ou mesmo com os atores externos. Aumentou o número de nós soltos: @A4; @A5; @A8; @A12; @B2; @Ex3; @ucbrasil, que podem ser considerados atores que só se conectavam à rede por intermediação do professor.

Analisar o conteúdo das mensagens permitiu qualificar o tipo de conteúdo trocado entre os alunos da disciplina que formaram a rede \#infobiblio. Nesse primeiro grupo de mensagens foram reunidas as que demonstram a apropriação dos alunos e as primeiras impressões quanto ao uso da ferramenta recomendada:

@ A18 no laboratório esperando o profe começar a aula \#infobiblio, 22 fev. 2011.

@A10 foi o máximo o prof ${ }^{\circ}$ ter solicitado criar um twitter para os alunos se comunicarem, sobre a diciplina \#infobiblio, 23 fev. 2011.

@ A20 Rafa...adorei a sua ideia de escrever uma resenha em 140 caracteres, seria um desafio massa =D \#infobiblio, 23 fev. 2011.

@ A18 To achando um máximo usar as redes sociais nas aulas \#infobiblio, 23 fev. 2011

@ A2 \#infobiblio cheguei no twitter ok?, 01 mar. 2011.

@ A15 \#infobiblio consegui., 01 mar. 2011.

@ A10 eu estou ainda muito perdido, no twitter \#infobiblio, 01 mar. 2011.

@ A16 ainda me adaptando ao twitter \#infobiblio, 01 mar. 2011.

@ A11 twitter, ferramenta legal!!! claro utilizado de maneira adequada \#infobiblio, 01 mar. 2011.

@ A13 No twitter também!! Se não souber argumentar e principalmente sintetizar as informações... pode ser um completo desastre \#infobiblio, 22 mar. 2011.

@A7 @A18 esse twitter ta virando vício rsrs \#infobiblio, 05 abr. 2011.

Sabemos que com os recursos da web 2.0 no contexto educacional cada alunos é estimulado a produzir e socializar conteúdos. Foram identificadas mensagens nas quais os alunos apresentam suas dúvidas, elaboram questões ou compartilham parte do conteúdo aprendido na disciplina.

@ A18 as redes sociais algumas vezes fazem os estudos parecerem mais leves, a gente informa e aprende sem parecer uma obrigação. \#infobiblio, 28 fev. 2011.

@13 Ainda não sei me posicionar quanto ao papel do bibliotecário nas mídias sociais. =0 \#infobiblio, 22 mar. 2011.

@ A10 são muitos itens utilizados das midias sociais nas unidades de informação? \#infobiblio, 22 mar. 2011.

@ A2 A web 2.0 é um espaço onde as pessoas podem interagir, trocar informações, modificar e criar conteúdos.\#infobiblio, 05 abr. 2011.

@ A3 \#infobiblio Web 2.0 ou Web Social é uma nova concepção de internet, que possibilita a criação de espaços cada vez mais interativos., 05 abr. 2011.

@ A13 Primeira palavra que vem a cabeça quando se fala em biblioteca 2.0 é interatividade, biblioteca + bibliotecário + usuário. \#infobiblio, 05 abr. 2011.

InCID: R. Ci. Inf. e Doc., Ribeirão Preto, v. 4, n. 1, p. 163-181, jan./jun. 2013. 
O próximo agrupamento de mensagens reúne tweets que indicam o uso do Twitter para comunicação entre os alunos da turma. Nele constam mensagens de aviso, comunicados e indicação de textos, perguntas feitas pelos alunos ao professor, dentre outras:
@PROF Vamos observar a capacidade de síntese dos aspectos relevantes da disciplina \#infobiblio bem como as respostas (replies) e reproduções (RTs). 23 fev. 2011.
@PROF Atenção alunos da \#infobibio segue o link do artigo que falei na aula sobre tags afetivas no twitter http://dgz.org.br/dez10/F_I_art.htm. 01 mar. 2011.
@A10 @PROF vc vai trabalhar com algum texto na aula de \#infobiblio se for qual?, 28 mar. 2011. @ A11 @PROF Quais os assuntos para a prova de terça-feira???? \#infobiblio, 09
abr. 2011.
@A07 @PROF professor diga minha nota por favor pode ser por aqui no twitter \#infobiblio, 12 abr. 2011
@A07@PROF Prof. o texto pra proxima aula vai ser Catálogos on-line? \#infobiblio, 13 abr. 2011.
@A16@PROF ficou satisfeito com o dezempenho da turna na prova de \#infobiblio ?????, 19 abr. 2011.
@ A01 texto p/ prox aula - catalogos online http://www.sibi.ufrj.br/snbu/snbu2002/oralpdf/70.a.pdf \#infobiblio, 26 abr. 2011.

Das 514 mensagens analisadas, apenas 23 foram enviadas pelo professor, ou seja, $95 \%$ delas foram enviadas pelos alunos e outros atores. Reconhecemos a partir desse quantitativo alguns aspectos próprios do uso de recursos da web 2.0 no contexto educacional apresentados por Grosseck, Marinho e Tárcia (2009) como a modificação do paradigma clássico da geração e da transmissão de conhecimento, no envolvimento ativo e exercício da autonomia por parte dos alunos.

Uma breve análise de conteúdo das mensagens, na busca dos termos de maior frequência, para indicar o que é mais comentado pelos alunos foi feita e pode ser visualizada na Figura 1, que expressa com destaque, pelo maior tamanho da fonte, os termos com mais recorrentes. 


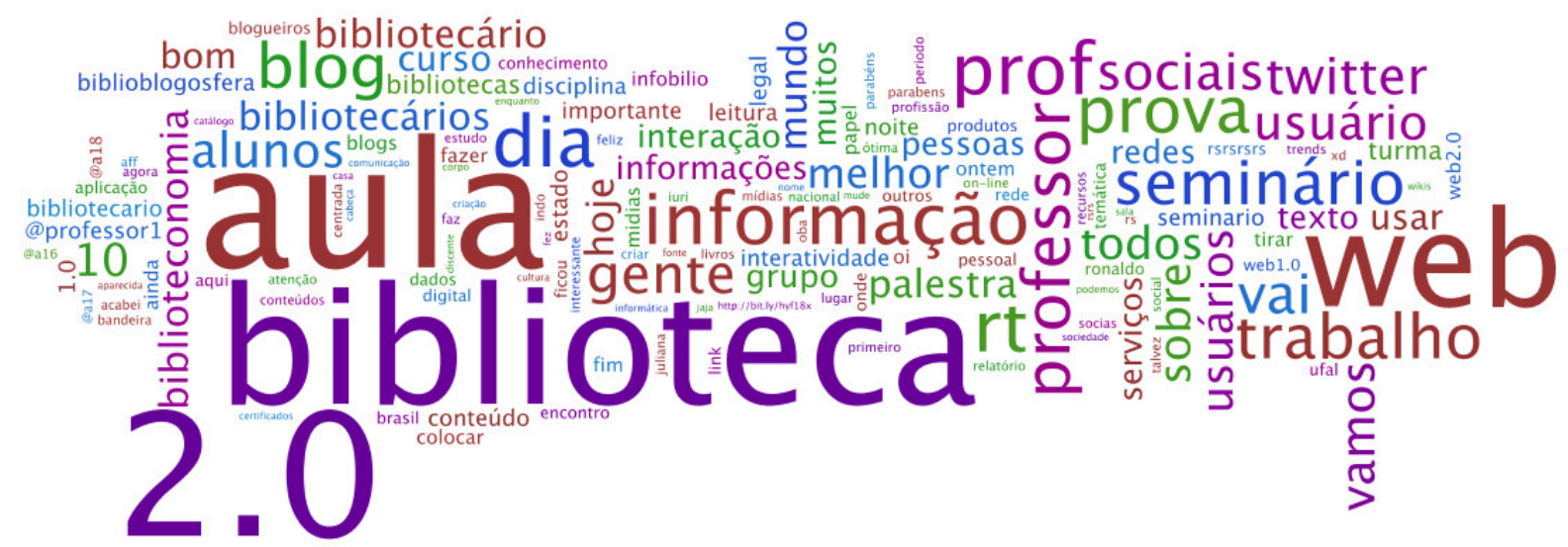

Figura 1 - Nuvem de termos mais recorrentes Fonte: Elaborada pelo autor a partir do Many Eyes ${ }^{9}$

Os termos "biblioteca 2.0", "web 2.0", e "aula" constam em mais de 40 mensagens cada, sendo os mais recorrentes e mostrando que a centralidade da discussão está em torno do objeto da disciplina. Outros termos como "palestra", "seminário", "trabalho" e "prova" com frequência entre 15 a 31 mensagens cada, indicam o compartilhamento de informações em torno das atividades desenvolvidas na disciplina.

Ao final da disciplina os alunos foram questionados sobre como foi sua experiência na utilização de blogs e redes sociais na internet ao longo do semestre. A maioria (82\%) demonstrou sua preferência pelo Twitter destacando (a) algumas de suas vantagens: "agilidade com que qualquer notícia ou comentário chega para outros usuários (seguidores)" A18; "ajuda a desenvolver a capacidade de síntese do usuário e sua interatividade aproxima as pessoas" - A18; "facilidade da recuperação [da informação] por meio da tag(hashtag)" - A7; "permite a comunicação e a troca de informação entre os usuários, mesmo quando não somos seguidores" - A19; "permite disseminar informações e interagir com outros usuários e durante as atividades se tornou uma importante ferramenta, onde foi possível expor minhas opiniões e compartilhar os conteúdos da disciplina" - A16; e outras (b) outras impressões: "foi o ambiente em que eu só tinha ouvido falar e a interação acabou sendo uma experiência inovadora" - A17; "não tinha noção, não gostava, mas percebi sua agilidade em transmitir informação para várias pessoas ao mesmo tempo" - A5; "eu não utilizava antes por achar que as outras (ferramentas) utilizadas já eram suficientes, e hoje vejo o twitter (e os blogs) como parte de um processo de disseminação do conhecimento" - A8.

\footnotetext{
${ }^{9}$ Visualizador de dados criado em 2007 pela Visual Communication Lab , parte do grupo Collaborative User Experience da IBM Research. Acesso em: http://www-958.ibm.com/software/data/cognos/manyeyes/
}

InCID: R. Ci. Inf. e Doc., Ribeirão Preto, v. 4, n. 1, p. 163-181, jan./jun. 2013. 


\section{Considerações finais}

O trabalho procurou refletir sobre o uso dos recursos da web 2.0 no apoio ao processo de ensino aprendizagem como uma forma de prática pedagógica interativa. A disciplina na qual houve o experimento e relato aqui apresentado foi ministrada durante o primeiro semestre de 2011 às terças-feiras das 19 h as 22h20. Os gráficos que apresentam a distribuição das mensagens por dia da semana e horário do dia corroboram com o discutido no trabalho. Uma vez que obtivemos um número significativo de mensagens em todos os demais dias da semana e em outros horários do dia, comprovamos que o recurso da web 2.0 utilizado corrobora com a noção de aprendizagem distributiva e contínua apresentada por Grosseck, Marinho e Tárcia (2009) na qual o assunto discutido ultrapassa as limitações espaço-temporal da sala de aula uma vez que "ganha" a rede e suas múltiplas possibilidades.

As 514 mensagens analisadas correspondem aos tweets que foram sinalizadas com a hashtag da disciplina. Como o uso da hashtag é algo próprio do Twitter e que precisa ser aos poucos incorporado na prática do usuário considera-se que muitas outras mensagens, que não tiveram sua devida sinalização, se perderam na rede.

Pimentel e outros (2009) relatam que há pouca pesquisa que revele como os usuários brasileiros estão se apropriando desta ferramenta microblog como potencialidade educacional, inclusive deixam o questionamento quanto a relevância pedagógica de utilizá-la. Com o presente trabalho procuramos contribuir com a discussão, sendo um trabalho que busca refletir sobre o tema e que, além disso, comprova o uso e suas contribuições na prática pedagógica.

Na percepção dos alunos foi possível verificar como os mesmos enxergaram o uso do twitter e suas vantagens para disseminação e compartilhamento da informação bem como as possibilidades de colaboração do microblog. Nessa prática pedagógica interativa, devido suas implicações na reconfiguração dos papéis e sua dinâmica na construção de percursos individuais e principalmente coletivos no processo de aprendizagem, talvez já não seja tão adequado enxergar os recursos da web 2.0 como ferramentas, e sim, para além do uso utilitário, pensá-los como uma nova linguagem. 


\section{Referências}

ARAUJO, R. F.; VIEIRA, R. M. Blogosfera como rede social: análise da interatividade dos blogs de Alagoas. Informe: Estudos em Biblioteconomia e Gestão da Informação, v.1, n.1, p. 2012. Disponível em: <http://www.repositorios.ufpe.br/index.php/informe/article/view/16>. Acesso em: 05 jun. 2012.

ABRAM, S. 15 Minutes a day: a personal learning management strategy. One-Person Library, v. 24, n. 2, p. 5-7, Jun., 2007.

ABECIN - Associação Brasileira de Educação em Ciência da Informação. Relatórios e Planos de Gestão: 2004/2007. Disponível em: < http://www.abecin.org.br>. Acesso em: 22 mar. 2012.

BECKER, F. A epistemologia do professor: o cotidiano da escola. 6. ed. Petrópolis: Vozes, 1998. 344p.

BLATTMANN, U; CORRÊA DA SILVA, F. C. Colaboração e interação na Web 2.0 e Biblioteca 2.0. Revista ACB: Biblioteconomia em Santa Catarina, Florianópolis, v.12, n.2, p.191-215, jul./dez., 2007. Disponível em:

<http://revista.acbsc.org.br/index.php/racb/article/view/530/664>. Acesso em: 06 jan. 2010.

BOYD, D. M.; ELLISON, N. B. Social network sites: definition, history, and scholarship. Journal of Computer-Mediated Communication, v. 13, n. 1, 2007. Disponível em: $<$ http://jcmc.indiana.edu/vol13/issue1/boyd.ellison.html>. Acesso em: 07 jan. 2012.

CAMARGO, R. A interação enquanto característica comum entre blogs e Twitter. 2008. 71f. Monografia (Bacharelado em Jornalismo), Faculdade de Ciências Sociais Aplicadas, Centro Universitário Newton Paiva, Belo Horizonte, 2008. Disponível em:

$<$ http://www.scribd.com/doc/11446750/Interacao-Em-Blogs-e-Twitter $>$. Acesso em 12 maio 2012.

CUNHA, M. I. O professor universitário na transição de paradigmas. Araraquara: JM, 1998.

CASTRO, C. A. Tendências pedagógicas no ensino de biblioteconomia e ciência da informação. In: __ (Org). Conhecimento, pesquisa e práticas sociais em ciência da informação. São Luis: EDUFMA, 2007. p. 131-142.

GROSSECK, G.; MARINHO, S. P. P.; TÁRCIA, L.. Educação a distância baseada na Web 2.0: a emergência de uma pedagogia 2.0. Educação \& Linguagem, v. 12, n. 19, p. 111-123, jan./jun. 2009. Disponível em: < https://www.metodista.br/revistas/revistasims/index.php/EL/article/viewFile/816/884 >. Acesso em: 05 mar. 2012.

HAGUENAUER, C. J.; PEDROSO, T. P. Uso de plataformas de gerenciamento de ensino online: no ensino à distância e no apoio ao ensino presencial. In: COBENGE, 31., Rio de Janeiro, 2003. Anais... Rio de Janeiro: ABENGE, 2003. 
FERREIRA, G. I. S. A prática reflexiva do professor de Biblioteconomia: transposição didática. Porto Alegre. 1999. Dissertação de Mestrado. Faculdade de Educação. Pontifícia Universidade Católica do Rio Grande do Sul (PUC/RS).

FERREIRA, G. I. S. A prática pedagógica do professor de Biblioteconomia. Congresso Brasileiro de Biblioteconomia e Documentação, Porto Alegre, RS. 2000. Anais... Porto Alegre, 2000a.

FERREIRA, G. I. S. A prática pedagógica do professor de Biblioteconomia: transposição didática. Revista de Biblioteconomia e Comunicação, Porto Alegre, RS, v. 8, p. 57-74, 2000b.

GUTIERREZ, S. S. Professores conectados: trabalho e educação nos espaços públicos em rede. Porto Alegre, 2010. 277 f. Tese (Doutorado em Educação) - Programa de PósGraduação em Educação, Faculdade de Educação, Universidade Federal do Rio Grande do Sul, Porto Alegre, 2010.

HILLESHEIM, A. I. A. A prática pedagógica no Curso de Biblioteconomia da UFSC: discurso dos docentes do CIN e dos alunos do curso. Florianópolis, 2001. 253 f. Dissertação (Mestrado em Educação) - Programa de Pós-Graduação em Educação, Universidade Federal de Santa Catarina, Florianópolis, 2001.

LÉVY, P. Cibercultura. São Paulo: 34, 1997.

LÉVY, P. A revolução contemporânea em matéria de comunicação. In: MARTINS, F. M. et.al. Para entender o século XXI: tecnologias do imaginário e cibercultura. Porto Alegre: EDIPUCRS, 2000.

LIMA, L. C. C. Análise das práticas docentes de planejamento e mediação em redes sociais no ensino médio. 2011. 132 f. Dissertação (Mestrado em Ciência da Computação) Programa de Pós-Graduação em Ciência da Computação, Universidade Federal de Pernambuco, Recife, 2011.

MANESS, J. M. Teoria da biblioteca 2.0: Web 2.0 e suas implicações para as bibliotecas. Informação \& Sociedade, João Pessoa, v. 17, n. 1, p.43-51, jan./abr., 2007. Disponível em: $<$ http://periodicos.ufpb.br/ojs2/index.php/ies/article/view/831/1464>. Acesso em: 12 fev. 2009.

PEREIRA, D. C.; CRUZ, R. C. Folksonomia e tags afetivas: comunicação e comportamento informacional no Twitter. Datagramazero, Rio de Janeiro, v. 11, p. 6, 2010.

PIMENTEL, F. S. C.; SILVA, I. P.; SANTOS, C. N.; MERCADO, L. P. L. Microblogs e seu potencial de uso em educação. In: INTERNATIONAL SYMPOSIUM ON COMPUTERS IN EDUCATION, 11., 2009, Coimbra. Proceedings... Coimbra, 2009.

PRIMO, A. O aspecto relacional das interações na Web 2.0. Brasília, E-Compós, v. 9, p. 121, 2007. Disponível em: <http://www6.ufrgs.br/limc/PDFs/web2.pdf>. Acesso em: 29 jul., 2009.

RECUERO, R. Redes sociais na Internet. Porto Alegre: Sulina, 2009

InCID: R. Ci. Inf. e Doc., Ribeirão Preto, v. 4, n. 1, p. 163-181, jan./jun. 2013. 
RECUERO, R.; ZAGO, G. "RT, por favor": considerações sobre a difusão de informações no Twitter. Revista Fronteiras - estudos midiáticos, v. 12, n. 2, maio/ago. 2010.

RODRIGUES, M. E. F. O paradigma emergente e a abordagem do ensino com pesquisa: uma proposta de resignificação para o ensino de Biblioteconomia e Ciência da Informação. 2008. Tese (Doutorado em Ciência da Informação) - Escola de Ciência da Informação, universidade Federal de Minas Gerais. Belo Horizonte, 2008.

RODRIGUES, M. E. F. As práticas pedagógicas no processo de ensino aprendizagem do profissional da informação: desafios e perspectivas de mudanças. In: ENCONTRO NACIONAL DE PESQUISA EM CIÊNCIA DA INFORMAÇÃO, 12., Brasília, 2011. Anais... Brasília: ANCIB, 2011. 